\title{
A tool for predicting the dynamic response of biotrickling filters for VOC removal
}

\author{
P. San-Valero ${ }^{\mathrm{a}}$, S. Alcántara ${ }^{\mathrm{b}}$, J.M. Penya-roja ${ }^{\mathrm{a}}$, F.J. Álvarez-Hornos ${ }^{\mathrm{a}}$, C. Gabaldón ${ }^{\mathrm{a}, *}$ \\ ${ }^{a}$ Research Group GI ${ }^{2} A M$, Department of Chemical Engineering, University of Valencia, Avda. Universitat \\ $s / n, 46100$ Burjassot, Spain \\ ${ }^{b}$ PAS Solutions BV, P.O. Box 135, 8440 AC Heerenveen, The Netherlands
}

\begin{abstract}
This article presents the development of a MATLAB ${ }^{\circledR}$ computer program to simulate the performance of biotrickling filters. Since these filters behave differently during spraying and non-spraying cycles, the presented simulation tool is built on top of a mathematical description of each situation. The resulting variable-structure model is then used as the basis for simulation experiments. The model presented herein represents the first attempt to take into account the variable spraying pattern usually found in industrial installations. Overall, the software is flexible and easy to use, allowing the user to specify the emission concentration pattern, the gas concentration pattern, as well as the spraying cycles period for up to two different emission patterns per day. The model is able to predict experimental data from a biotrickling filter treating isopropanol under intermittent conditions of loading and spraying. Simulation examples are then provided to study the effect of variable inlet
\end{abstract}

\footnotetext{
*Address correspondence to C. Gabaldón. Research Group GI ${ }^{2}$ AM, Department of Chemical Engineering, University of Valencia, Avda. Universitat s/n, 46100 Burjassot, Spain Tel.: +34 963543437; fax: +34 963544898. E-mail address: carmen.gabaldon@uv.es
} 
concentration and gas flow rates.

Keywords: VOC, Biotrickling filters, Mathematical modelling, Numerical analysis, Computer simulation

\section{Introduction}

2 Emission to the atmosphere, from a wide variety of sources, of volatile organic compounds (VOCs) remains one of the most important causes of air pollution. This has 4 trigerred significant research efforts to develop more cost-effective and environmentally 5 friendly solutions for the treatment of air emissions of VOCs. In particular, there has 6 been an increasing interest in biofiltration, especially since it has been classified as a best 7 available technique (BAT) by the European Commission (2003). Among the biofiltration 8 strategies, biotrickling filters (BTFs) constitute one of the most suitable biotechnologies 9 for the treatment of VOCs. Biotrickling filters consist of a column filled with an inert 10 packing material where the biomass attaches to the media and develops a biofilm. In this configuration, the gas and liquid phases circulate through the column in co- or countercurrent mode. Thus, the pollutant and the oxygen are transferred from the gas phase to the trickling liquid, and then to the biofilm, where the biodegradation takes place.

Biotrickling filtration has been applied successfully to the treatment of VOCs at the laboratory, pilot, and industrial scales. However, to further improve the performance of

BTFs for the treatment of VOCs it has become necessary to understand the intricacies of 
the processes involved as well as their rate-limiting steps (Popat and Deshusses, 2010). In this regard, biotrickling filtration involves a complex set of physico-chemical and biological mechanisms and, hence, mathematical models, in conjunction with computer-aided simulation, appear as fundamental tools to go deeper into the understanding of the involved governing processes.

Industrial processes that use solvents are characterized by fluctuating VOC emissions arising from the specific application and the unit operations dynamics of each particular industry (Rene et al., 2013). These results in emission levels whose time variations are related to random fluctuations of the gas velocity and the inlet concentration profile. In addition, short-time shut-off periods associated with nights, weekends and holiday closures further contribute to create a variable pattern of VOC emissions at the industrial scale. This variability may sometimes hinder the performance of field-scale BTFs (Sempere et al., 2010). Also, operating BTFs under cyclic and discontinuous operation has traditionally produced some problems, as reported in Webster et al. (1999).

Intermittent water trickling, in contrast to continuous trickling, is also common practice in the operation of industrial BTFs. As shown in Sempere et al. (2008), intermittent trickling may improve the removal efficiency and better control the pressure drop. The final performance of the BTF is quite dependent on the rate of liquid trickling (Zhu et al., 1998). An intermittent spraying regime implies that the mobile liquid phase is not al- 
ways present during the filter operation, making it necessary to distinguish two different situations, corresponding to spraying and non-spraying periods. Nevertheless, the modelling and simulation research presented in the literature so far tends to focus only on one particular case.

Several efforts have been made to model biofiltration processes. One of the most used models for the treatment of organic pollutants in waste gases in a gas-liquid biofilter has been developed by Ottengraf and Van Den Oever (1983) in steady state conditions. Since then, there has been increasing interest in the application of dynamic models of biofilters and BTFs rather than of steady state models. Shareefdeen and Baltzis (1994) published one of the first attempts to describe the dynamic behaviour of biofilters, including the oxygen limitation in the biofilm and the adsorption phenomena. Deshusses et al. (1995) proposed a model for the determination of transient and steady-state conditions degrading MEK and MIK emissions in biofilters. Zarook et al. (1997) developed a transient biofiltration model that incorporates oxygen limitation effects, general mixing and adsorption phenomena, as well as general biodegradation reaction kinetics. Thereafter, many researchers introduced variations of these models by adding new considerations. Métris et al. (2001) used a simplication of the Zarook et al. (1997) model using $\mathrm{CO}_{2}$ production to evaluate the response of the biofilters to starvation and shock loads in the biofiltration of toluene and xylene. Álvarez Hornos et al. (2009) developed a dynamic model with a Haldane-type 
kinetic expression that considers oxygen limitation, (cross) inhibition effects due to high concentration of substrates, and a general axial gradient equation for the biomass density. Many BTF models derive from biofilter models. Okkerse et al. (1999) presented a detailed dynamic model that includes the growth of methylene chloride degraders and inert biomass as well as the effect of $\mathrm{pH}$ and dissolved oxygen. Kim and Deshusses (2003) presented a three-phase dynamic model to describe the biotrickling filtration of hydrogen sulfide with a gas and liquid flowing counter-currently. They assumed that the biofilm was not completely wetted by the liquid phase and thus, in some parts of the biofilm, the pollutant was transferred directly from the gas phase to the biofilm. In their review of biofilters and biotrickling modelling, Devinny and Ramesh (2005) pointed out that no single model has become generally accepted. The complexity behind the operation of BTFs has made many researchers consider specific situations in their simulation studies (Lee and Heber, 2010; Mannucci et al., 2012).

The increase in the number of factors taken into consideration in the mathematical models has necessitated greater efforts for their mathematical solution. In the case of models of biotrickling filters, the presence of the liquid phase implies an increase of the level of complexity and for counter current operation, which is usual found in the industry, the system of equations obtained can be relatively stiff and model instabilities could make their solution difficult (Deshusses and Shareefdeen, 2005). Even so, it has been recognized 
that realistic models adapted to the emissions of the industry are needed.

The aim of this paper is to present a more flexible tool to simulate the performance of BTFs. Based on the operational conditions commonly found in industry, the proposed model allows specifying variable inlet concentration patterns and gas velocities combined with different spraying patterns. These and other features provide the necessary flexibility to reproduce typical industrial use cases.

\section{Model development}

Industrial BTFs operate with intermittent water trickling. This means that the mobile liquid phase is only present at some times during the day, referred to here as the spraying periods. For the rest of the time, referred to as the non-spraying periods, the liquid phase remains as a stagnant phase. Figure 1 illustrates this concept. The modelling step has to take into account the principal mechanisms of the biofiltration process in each situation. In this configuration, the pollutant/oxygen is transferred from the gas phase to the liquid phase and then to the biofilm as is represented in Figure 2. The model has been developed following the general mass balances of gas phase, liquid phase and biofilm by taking into account the most important phenomena compiled by Devinny and Ramesh (2005). 
For the model derivation, the following general assumptions have been made based on consolidated models reported (Kim and Deshusses, 2003; Mpanias and Baltzis, 1998) and adapted to this model.

(1) The gas phase flows in a plug flow regime along the filter bed.

(2) Axial dispersion is neglected.

(3) The adsorption of pollutant in the packing material is negligible.

(4) The active biofilm is formed on the external surface of the packing material and no reaction occurs in the pores. The biofilm covers the surface of the packing material and its thickness $(\delta)$ is much smaller than the size of the solid particles, so a planar geometry has been assumed.

(5) The packing material is completely covered by the biofilm.

(6) The diffusion of the biofilm is described by Fick's law.

(7) Ideal conditions of nutrients and $\mathrm{pH}$ are assumed.

(8) The system works under cycling conditions of spraying/non-spraying periods.

(9) The status reached at the end of one period determines the initial conditions for the next period.

(10) The biodegradation kinetics is described by a Monod expression, which takes into account the oxygen limitation.

(11) The mass flux at the gas-liquid interface can be expressed by mass transfer coeffi- 
cients.

(12) The mass flux at the liquid-biofilm interface can be expressed by mass transfer coefficients.

(13) There is no reaction in the liquid phase.

(14) The gas-liquid interface is in equilibrium according to Henry's law.

Based on the assumptions above, the mass balances for the different phases can be written as follows:

Spray mode

Mass balance in the gas phase.

$$
\begin{aligned}
\theta_{G} \frac{\partial C_{G_{P}}}{\partial t} & =-v_{G} \frac{\partial C_{G_{P}}}{\partial z}-\alpha_{1} K_{L} a_{P}\left(\frac{C_{G_{P}}}{H_{P}}-C_{L_{P}}\right) \\
\theta_{G} \frac{\partial C_{G_{O}}}{\partial t} & =-v_{G} \frac{\partial C_{G_{O}}}{\partial z}-\alpha_{1} K_{L} a_{O}\left(\frac{C_{G_{O}}}{H_{O}}-C_{L_{O}}\right)
\end{aligned}
$$

where, for the pollutant and oxygen, respectively, $C_{G_{P}}$ and $C_{G_{O}}$ are the concentration in the gas phase, $K_{L} a_{P}$ and $K_{L} a_{O}$ are the overall mass transfer coefficients, $\alpha_{1}$ is the correction factor of the overall mass transfer coefficients, $H_{P}$ and $H_{O}$ are the dimensionless Henry's law constants expressed as concentration of the gas phase/ concentration of the liquid phase, $C_{L_{P}}$ and $C_{L_{O}}$ are the concentration of the liquid phase. $t$ denotes the time, $z$ is the distance from the bottom of the column and $v_{G}$ is the superficial air velocity given by

$$
v_{G}=\frac{Q_{G}}{\frac{\pi D^{2}}{4}}
$$


where $Q_{G}$ is the volumetric gas flow rate and $D$ is the column diameter.

$\theta_{G}$ is the porosity of the bioreactor and is given by

$$
\theta_{G}=1-\left(1-\theta_{p m}\right)-\theta_{L}-\theta_{B}
$$

where $\theta_{p m}$ is the void fraction of the packing material, $\theta_{L}$ is the fraction occupied by the liquid film and $\theta_{B}$ is the fraction occupied by the biofilm.

The boundary conditions of Equations 1 and 2 are

$$
\begin{gathered}
C_{G_{P}}=C_{G_{P}}^{i n} \text { at } z=0 \\
C_{G_{O}}=C_{G_{O}}^{i n} \quad \text { at } z=0
\end{gathered}
$$

Mass balance in the liquid phase.

$$
\begin{aligned}
& \theta_{L} \frac{\partial C_{L_{P}}}{\partial t}=v_{L} \frac{\partial C_{L_{P}}}{\partial z}+\alpha_{1} K_{L} a_{P}\left(\frac{C_{G_{P}}}{H_{P}}-C_{L_{P}}\right)-\frac{D_{w_{P}} A}{\beta}\left(C_{L_{P}}-S_{P_{1}}\right) \\
& \theta_{L} \frac{\partial C_{L_{O}}}{\partial t}=v_{L} \frac{\partial C_{L_{O}}}{\partial z}+\alpha_{1} K_{L} a_{O}\left(\frac{C_{G_{O}}}{H_{O}}-C_{L_{O}}\right)-\frac{D_{w_{O}} A}{\beta}\left(C_{L_{O}}-S_{O_{1}}\right)
\end{aligned}
$$

where, for the pollutant and oxygen, respectively, $S_{P_{1}}$ and $S_{O_{1}}$ are the concentration in the biofilm interface, $\beta$ is the thickness of the liquid-biofilm interface, $D_{w_{P}}$ and $D_{w_{O}}$ are the diffusion coefficient in water, $A$ is the specific surface area, $x$ is the axial position along the biofilm, and $v_{L}$ is the superficial liquid velocity given by 


$$
v_{L}=\frac{Q_{L}}{\frac{\pi D^{2}}{4}}
$$

The boundary conditions of Equations 6 and 7 are

$$
\begin{array}{cc}
\frac{\partial C_{L_{P}}}{\partial t}=\frac{Q_{L}}{V_{T}}\left(C_{L_{P(z=0)}}-C_{L_{P(z=Z)}}\right) & \text { at } z=Z \\
\frac{\partial C_{L_{O}}}{\partial t}=\frac{Q_{L}}{V_{T}}\left(C_{L_{O(z=0)}}-C_{L_{O(z=Z)}}\right) & \text { at } z=Z
\end{array}
$$

The boundary conditions given by Equation 9 correspond to the mass balances in the recirculation tank, where $V_{T}$ is the water volume in the recirculation tank. It is assumed that the liquid inlet concentration in the column is equal to the concentration in the recirculation tank, and that the recirculated water depends on the liquid concentration at the bottom of the column.

Mass balance in the biofilm.

$$
\begin{aligned}
\frac{\partial S_{P}}{\partial t} & =D_{P_{B}} \frac{\partial^{2} S_{P}}{\partial x^{2}}-\frac{\mu_{\max } X_{v}}{Y_{P}} \frac{S_{P}}{S_{P}+K_{P}} \frac{S_{O}}{S_{O}+K_{O}} \\
\frac{\partial S_{O}}{\partial t} & =D_{O_{B}} \frac{\partial^{2} S_{O}}{\partial x^{2}}-\frac{\mu_{\max } X_{v}}{Y_{O}} \frac{S_{P}}{S_{P}+K_{P}} \frac{S_{O}}{S_{O}+K_{O}}
\end{aligned}
$$

where $S_{P}$ and $S_{O}$ are the concentration in the biofilm. The boundary conditions are given 


$$
\begin{array}{cc}
\frac{\partial S_{P}}{\partial t}=0 \quad \text { at } x=\delta \\
\frac{\partial S_{O}}{\partial t}=0 & \text { at } x=\delta
\end{array}
$$

147

Mass balance in the gas phase.

$$
\begin{aligned}
\theta_{G} \frac{\partial C_{G_{P}}}{\partial t} & =-v_{G} \frac{\partial C_{G_{P}}}{\partial z}-\alpha_{2} \alpha_{1} K_{L} a_{P}\left(\frac{C_{G_{P}}}{H_{P}}-C_{L_{P}}\right) \\
\theta_{G} \frac{\partial C_{G_{O}}}{\partial t} & =-v_{G} \frac{\partial C_{G_{O}}}{\partial z}-\alpha_{2} \alpha_{1} K_{L} a_{O}\left(\frac{C_{G_{O}}}{H_{O}}-C_{L_{O}}\right)
\end{aligned}
$$


with the boundary conditions

$$
\begin{gathered}
C_{G_{P}}=C_{G_{P}}^{i n} \text { at } z=0 \\
C_{G_{O}}=C_{G_{O}}^{i n} \text { at } z=0
\end{gathered}
$$

Mass balance in the liquid phase.

$$
\begin{aligned}
& \theta_{L} \frac{\partial C_{L_{P}}}{\partial t}=\alpha_{2} \alpha_{1} K_{L} a_{P}\left(\frac{C_{G_{P}}}{H_{P}}-C_{L_{P}}\right)-\frac{D_{w_{P}} A}{\beta}\left(C_{L_{P}}-S_{P_{1}}\right) \\
& \theta_{L} \frac{\partial C_{L_{O}}}{\partial t}=\alpha_{2} \alpha_{1} K_{L} a_{O}\left(\frac{C_{G_{O}}}{H_{O}}-C_{L_{O}}\right)-\frac{D_{w_{O}} A}{\beta}\left(C_{L_{O}}-S_{O_{1}}\right)
\end{aligned}
$$

Mass balance in the biofilm.

$$
\begin{gathered}
\frac{\partial S_{P}}{\partial t}=D_{P_{B}} \frac{\partial^{2} S_{P}}{\partial x^{2}}-\frac{\mu_{\max } X_{v}}{Y_{P}} \frac{S_{P}}{S_{P}+K_{P}} \frac{S_{O}}{S_{O}+K_{O}} \\
\frac{\partial S_{O}}{\partial t}=D_{O_{B}} \frac{\partial^{2} S_{O}}{\partial x^{2}}-\frac{\mu_{\max } X_{v}}{Y_{O}} \frac{S_{P}}{S_{P}+K_{P}} \frac{S_{O}}{S_{O}+K_{O}}
\end{gathered}
$$

with the boundary conditions

$$
\begin{array}{ll}
\frac{\partial S_{P}}{\partial t}=0 \quad \text { at } x=\delta \\
\frac{\partial S_{O}}{\partial t}=0 & \text { at } x=\delta
\end{array}
$$




\section{Numerical solution}

The partial differential equations (1), (2), (6), (7), (10), (11) (spray mode), and (14), (15), (17), (18), (19), and (20) (non-spray mode) constitute two second order nonlinear distributed systems. In order to solve them, the method of lines (MOL) (Schiesser, 1991, 1994; Schiesser and Griffiths, 2009) has been chosen. Although the finite difference method (FDM) has previously been used in the literature to simulate biofilter and biotrickling filters (Ikemoto et al., 2006; Álvarez Hornos et al., 2009) in different ways, the MOL has some advantages that make it more suitable here. Apart from its simplicity, it allows taking advantage of the available ODE solvers. Note, in addition, that the overall MOL process can be regarded as an FDM procedure where the discretization in $t$ is independent of that in $x, z$, which provides extra flexibility. Since the resulting systems have been found to be stiff, as is normally the case when applying the MOL (Schiesser, 1994), the ODE23t solver from the MATLAB ${ }^{\circledR}$ has been selected for solving the corresponding equations. The ODE23t is based on an implicit integration method and it is quite concerned with the stability issue. Other ODE solvers were tested, but the reported ODE gave the best results in practice. The MOL method is applied here following the steps:

- Generate a uniform grid in the space dimensions, i.e. $\left(x_{i}, z_{j}\right)_{i, j}$, where it is going to find an approximate solution. $Z$, the height of the column (the $z$ axis), is divided into $N$ sections. Similarly, the biofilm thickness $\delta$ is divided into $M$ sections with 
$M+1$ points. Values of $N=20, M=40$ are used for the spatial discretization in each mode.

- For each node in the grid, substitute the partial derivatives in the model equations with finite difference approximations.

- Solve the resulting system of ordinary differential equations (ODE) using standard numerical methods; note that the time variable $t$ was left continuous in the first step.

\section{Developed software tool}

The main objective of this paper is to introduce a tool for the simulation of biotrickling

filters using the mathematical models and numerical procedures described in the previous sections. This section describes the basic features implemented in the presented tool, focusing on its usability. The software has been developed in MATLAB ${ }^{\circledR}$. It can be used with the basic MATLAB ${ }^{\circledR}$ package and it is available as a MATLAB package as well as a compiled standalone application. The graphical user interface (GUI) has been created using the GUIDE-MATLAB ${ }^{\circledR}$ toolbox. A screenshot of the GUI is shown in Figure 3. In the present example, the option two emissions pattern (per day) allows specifying two different patterns of inlet concentration, gas velocity, and spraying, over a period of 86,400 seconds (i.e., one day). When this option is marked, the user indicates the duration of the first pattern $(<86,400$ seconds). The duration of the second pattern is then calculated 
automatically $(86,400$ seconds - time pattern 1$)$. The resulting global daily pattern is the combination of the two specified patterns in series, and the total simulation time in this case equals the number of days specified by the user.

[Figure 3 about here.]

The emission pattern and the spraying pattern are defined by the user by

- VOC inlet concentrations. For the inlet VOC concentration $\left(C_{G_{P}}^{i n}\right)$ pattern, a dropdown list presents the user with the following options for the input profile:

- Constant. The inlet concentration is assumed constant.

- Ramp+Constant. A constant concentration is considered as before, but preceded by a ramp pofile until the final value is reached.

- Pulse train. The inlet concentration oscillates between two values, describing a pulse train input signal.

- Piecewise constant. The inlet concentration consists of a step (or staircase) function, i.e., it is piecewise constant having only finitely many pieces.

After making a choice, a dialog window allows introducing the defining parameters for each case. For instance, for the Ramp+Constant profile, Figure 4 shows the resulting dialog. 
In contrast with the inlet VOC concentration, the inlet oxygen concentration $\left(C_{G_{O}}^{i n}\right)$ is assumed constant throughout the whole simulation $\left(276 \mathrm{~g} \mathrm{~m}^{-3}\right)$.

- Inlet gas flow pattern. This consists of a step (or staircase) function, i.e., it is piece-

[Figure 5 about here.]

The spraying panel includes the following information.

- Number of spray cycles $(n)$. Defines how many times to spray during each emission pattern.

- Spraying time $\left(T_{S}\right)$. Duration of spraying, i.e., the duration of the ON part of one spray cycle.

Simulation requires the user's specifying the initial conditions: 
- Initial conditions for the simulation experiment. This includes the VOC concentration in the liquid phase, the VOC concentration in the water tank, and the VOC concentration inside the biofilm and the oxygen concentration in the liquid concentration and inside the biofilm.

Input related to the BTF configuration, the pollutant and packing material data, and the model parameters are defined by the user:

- BTF set-up. This part defines the characteristics of the BTF system, such as the column diameter, column height, and the volume of the water tank. This panel provides automatically the column volume of the reactors.

- Physical properties. The physical properties panel includes the selection of the pollutant and the selection of the packing material. The selection of the pollutant uses a pop-up menu where it is possible to choose from among some predefined VOCs, whose information includes the diffusion coefficient in water $\left(D_{P_{w}}\right)$, the Henry's law constant $\left(H_{P}\right)$ at $25^{\circ} \mathrm{C}$, and the chemical formula. Alternatively, the user can select a user defined pollutant by specifying its diffusion coefficient in water, its Henry's law constant, and its chemical formula. The selection of the packing material uses another pop-up menu in which there are some predefined packing materials for each of which there are provided its specific surface area $(A)$, porosity $\left(\theta_{p m}\right)$, and specific coefficients to calculate the overall mass transfer coefficients $\left(K_{L} a_{P}, K_{L} a_{O}\right)$ using 
the correlations proposed by San-Valero et al. (2014). Alternatively, it is possible to define other packing material by specifying its specific surface area, porosity, and overall mass transfer coefficients.

- Hydrodynamic conditions such as liquid flow rate and fraction occupied by the liquid film.

- Biofilm properties. In this panel there should be indicated its biomass density $(X v)$, the thickness of its biofilm $(\delta)$, and its fraction occupied by the biofilm $\left(\theta_{B}\right)$.

- Kinetics data. In this panel the user indicates the kinetical parameters regarding to the pollutant degradation $\left(\mu_{\max }, K_{s}\right.$ and $\left.Y_{P}\right)$. Regarding the oxygen parameters, $K_{O}$ has been predefined from the literature as $0.26 \mathrm{~g} \mathrm{~m}^{-3}$ and $Y_{O}$ is calculated by stoichiometry balance.

- Advanced options. This button opens a dialog where other properties related with the mass transfer can be defined.

After all the input data and parameters have been defined, the simulation is run by pressing the Start button. When it concludes, the results are presented to the user in a new window, shown in Figure 6. The main items are described next.

[Figure 6 about here.] 
- A graph showing both the inlet and the outlet VOC concentrations in the gas phase (details about the information plotted in this graph will be given in Section 5).

- A graph showing the evolution of the VOC concentration in the liquid tank (details about the information plotted in this graph will be given in Section 5).

- Some relevant averages, over the whole simulation time, are displayed by this panel:

- Inlet/Outlet VOC concentration,

- Inlet load (IL) defined as

$$
I L\left(\frac{g-C}{m^{3} h^{1}}\right)=\frac{\overline{C_{G}^{i n}} \overline{Q_{G}}}{V_{R} 3600}
$$

where $\overline{C_{G}^{i n}}$ is the average inlet concentration and $\overline{Q_{G}}$ is the average of the gas flow rate.

- Removal efficiency (RE):

$$
R E(\%)=\frac{\overline{C_{G}^{\text {in }}}-\overline{C_{G}^{\text {out }}}}{\overline{C_{G}^{\text {in }}}} 100
$$

where $\overline{C_{G}^{\text {out }}}$ is the average outlet concentration

- Elimination Capacity (EC):

$$
E C\left(\frac{g-C}{m^{3} h^{1}}\right)=\frac{R E}{100} I L
$$


- Panel with averages for the emission pattern 1 only.

- Panel with averages for the emission pattern 2 only.

- This button allows exporting the simulation results to a Comma-Separated Values (CSV) file.

- Closes the results window.

\section{Model Calibration and Validation}

The model was calibrated and validated by using the experimental data corresponding to the dynamic response of a biotrickling filter treating isopropanol obtained by San-Valero et al. (2013). In this data, the BTF was operated under intermittent loading conditions and intermittent spraying frequency. These ones are typically found in the operation of industrial BTFs. During these experiments it was observed that the discontinuous regime of spraying of the bed resulted in outlet emissions of isopropanol during spraying periods. Based on this observation, the effect of the spraying pattern was evaluated and it was pointed out that the spraying frequency is a critical parameter to achieve low emissions.

The BTF was operated by using an IL of $32 \mathrm{~g}-\mathrm{Cm}^{-3} \mathrm{~h}^{-1}$ and empty bed residence time (EBRT) of $30 \mathrm{~s}$. The EBRT is defined as:

$$
\operatorname{EBRT}(s)=\frac{V_{R}}{\overline{Q_{G}}}
$$


These VOC feeding conditions were applied for a total time of $57600 \mathrm{~s}(16 \mathrm{~h})$ from 6:00 to 22:00h. The rest of the day, the biotrickling filter remained without VOC supply and without spraying. The parameters used in the modelling of the BTF behaviour are summarized in Table 1. The experimental parameters were taken from the literature or experimentally determined. The calibrated parameters were determined to fit the transient response data of the biotrickling filter. An independent experiment with a spraying pattern of 15 min every $1.5 \mathrm{~h}$ was used in the calibration step. Thus, time durations of 900 and $4500 \mathrm{~s}$ for the spraying and non-spraying periods, respectively, were set. In this experiment, it was assumed no mass transfer resistance at the gas-liquid interface $\left(\alpha_{2}=100\right)$. The comparison of experimental results and model predictions are shown in Figure 7. Figure 7(a) displays the evolution of the inlet and outlet VOC concentrations while Figure 7(b) displays the evolution of the concentration of carbon dissolved in the water tank.

[Table 1 about here.]

[Figure 7 about here.]

As it is shown in Figure 7(a), maximum concentrations of the pollutant are reached during the spraying periods, whereas during the non-spraying periods, nearly complete biodegradation of the pollutant is obtained. In addition, the peaks increase as the system gets filled with pollutant, reaching a stationary value for an outlet VOC concentration of around 0.2 
$\mathrm{g}-\mathrm{Cm}^{-3}$ after the third cycle. An EC of $27.2 \mathrm{~g}-\mathrm{Cm}^{-3} \mathrm{~h}^{-1}$ is obtained for an IL of 32 $\mathrm{g}-\mathrm{Cm}^{-3} \mathrm{~h}^{-1}$ during VOC feeding periods. The model successfully predicts the behaviour obtained, achieving maximum outlet concentrations during spraying periods at the last cycles of the day. The experimental data fits with the model prediction with a relative error less $3 \%$ in the EC (EC of the model $28.0 \mathrm{~g}-\mathrm{Cm}^{-3} \mathrm{~h}^{-1}$ ). Also, the model prediction for the carbon dissolved in the water tank is in good agreement with the measured carbon in the water tank.

The validation of the model was carried out by using data from two experiments. The first experiment was carried out with low spraying frequency of 15 min every $3 \mathrm{~h}$ and moderate IL $=32 \mathrm{~g}-\mathrm{Cm}^{-3} \mathrm{~h}^{-1}$. The second experiment was carried out with double spraying frequency (15 min every $1.5 \mathrm{~h})$ and double IL $\left(65 \mathrm{~g}-\mathrm{Cm}^{-3} \mathrm{~h}^{-1}\right)$. The experimental data and the model prediction are shown in Figure 8. Figure 8(a) displays the evolution of the inlet and outlet VOC concentrations for the first experiment while Figure 8(b) displays the evolution of the inlet and outlet VOC concentrations for the second experiment.

\section{[Figure 8 about here.]}

For the experiments carried out with a spraying regime of 15 min every 3 hours and IL of $32 \mathrm{~g}-\mathrm{Cm}^{-3} \mathrm{~h}^{-1}$, the relative error between experimental and simulated EC is $3.2 \%$ (experimental EC of $28.8 \mathrm{~g}-\mathrm{Cm}^{-3} \mathrm{~h}^{-1}$ and modelled EC of $29.7 \mathrm{~g}-\mathrm{Cm}^{-3} \mathrm{~h}^{-1}$ ). For the experiments carried out with a spraying regime of 15 min every 1.5 hours and an IL of 65 
$\mathrm{g}-\mathrm{Cm}^{-3} \mathrm{~h}^{-1}$, the error between the experimental and simulated EC is $4.0 \%$ (experimental EC of $50.3 \mathrm{~g}-\mathrm{Cm}^{-3} \mathrm{~h}^{-1}$ and modelled EC of $\left.52.3 \mathrm{~g}-\mathrm{Cm}^{-3} \mathrm{~h}^{-1}\right)$. The concentration of the dissolved carbon in the tank is in agreement with the measured values. As example, for the serie with a spraying regime of 15 min every 3 hours and IL of $32 \mathrm{~g}-\mathrm{Cm}^{-3} \mathrm{~h}^{-1}$, the measured dissolved carbon was $357 \mathrm{~g}-\mathrm{Cm}^{-3}$ and the model predicted a value of 365 $\mathrm{g}-\mathrm{Cm}^{-3}$, with a relative error of $2.2 \%$.

So, the model has been proven suitable in describing the complex phenomena observed in the transient response of the biotrickling filter to variations of the spraying pattern.

\section{Study of the dynamic response of the BTF to variable inlet concentrations and gas flow rates}

\section{Effect in the dynamic response of the BTF to oscillating inlet concentration}

The effect in the dynamic response of the BTF to oscillating inlet VOC concentration is investigated by using a periodic pulse train concentration pattern. The pulse train profile is used here to study the influence in the performance of high shock loads during regular changes in the operation. In particular, the selected inlet concentration takes on two alternating values: $C_{G_{P}}^{i n}=0.7 \mathrm{~g}-\mathrm{Cm}^{-3}$ (for $7200 \mathrm{~s}$ ) and $C_{G_{P}}^{i n}=0.2 \mathrm{~g}-\mathrm{Cm}^{-3}$ (for $3600 \mathrm{~s}$ ). A linear transition with a duration of 15 minutes is used to connect the two different values. A constant EBRT of $60 \mathrm{~s}$ is applied. Also, durations of 0.25 and 1 hours are specified for the spraying and non-spraying periods, respectively, and the pattern is applied for $T$ 
${ }_{348}=59400 \mathrm{~s}$. The simulation results are presented in Figure 9(a) for the gas phase and in

Figure 9(b) for the liquid phase. Figure 9(a) shows that the concentration peaks not only depend on the spraying cycles but also on the pattern of the inlet concentration. An EC of $30 \mathrm{~g}-\mathrm{Cm}^{-3} \mathrm{~h}^{-1}$ is obtained for an IL of $32 \mathrm{~g}-\mathrm{Cm}^{-3} \mathrm{~h}^{-1}$. The evolution of the VOC in the tank is presented in Figure9(b). To observe the accumulation of dissolved carbon in the water tank, in this example the concentration of dissolved carbon in the tank was set to $0 \mathrm{~g}-\mathrm{Cm}^{-3}$. In this example, two different phenomena can be observed: absorption and desorption processes. These processes are markedly dependent on the equilibrium between the gas and liquid phases. As can be observed, when the inlet concentration increases during the spraying periods, a desorption of pollutant from the liquid phase to the gas phase is produced, and the opposite occurs when the inlet concentration increases. At the end of the period, the water contains $200 \mathrm{~g}-\mathrm{Cm}^{-3}$ of dissolved carbon.

[Figure 9 about here.]

Effect in the dynamic response of the BTF to oscillating inlet concentration combined with spraying times during non-VOC feeding periods

[Figure 10 about here.]

The effect in the dynamic response of the BTF to oscillating inlet concentration combined with spraying times during non-VOC feeding periods is investigated. An oscillating 
emission pattern has been applied for a total of $59400 \mathrm{~s}$ per day. The inlet VOC concentration is exactly as the pulse train profile used in the previous example. A period without VOC feeding has been applied for $27000 \mathrm{~s}$ with a Ramp+Constant profile of $C_{G_{P}}=0.01$ $\mathrm{g}-\mathrm{Cm}^{-3}$ and a spraying time of 1 hour every $4 \mathrm{~h}$. The results for the gas and liquid phases, respectively, are shown in Figures 10(a) and 10(b). The combination of different input profiles leads to some remarkable observations of the behaviour of the system. Namely, the presence of dissolved VOCs in the water recirculation tank, combined with the spraying cycles during the shut-off periods, produces peaks of pollutant even in the absence of VOCs in the inlet stream. Also desorption is present during these periods. The decrease of these peaks during the shut-off periods are related to the transfer of VOCs to the column, where they get degraded.

\section{Effect in the dynamic response of the BTF to oscillating gas flow rates}

The effect of the gas flow rate on the BTF is carried out. A constant concentration of $C_{G_{P}}=0.53 \mathrm{~g}-\mathrm{Cm}^{-3}$ is selected. The gas flow rate takes on two alternating values: 4.8 $10^{-4} \mathrm{~m}^{3} \mathrm{~s}^{-1}$ and $6.810^{-5} \mathrm{~m}^{3} \mathrm{~s}^{-1}$ applied each one for periods of $14400 \mathrm{~s}$. Note that the average value of the EBRT is 60 seconds, as in the previously considered examples. The simulation results are shown in Figure 11. Figure 11(a) displays the evolution of the inlet and outlet VOC concentrations in the gas phase, Figure 11(b) displays the evolution of the concentration of carbon dissolved in the water tank, and Figure 11(b) represents 
the oscillating EBRT pattern. From Figure 11(a), the evolution of the peaks of the outlet gas concentration are different than those obtained in the previous examples. The gas velocity is directly related to the mass transfer of the pollutant between the gas and liquid phases, obtaining a greater mass transfer at large gas velocities, and thus, smaller EBRTs. The peaks obtained at the outlet VOC concentration pattern do oscillate according to the oscillating EBRT pattern. This contrasts with Figure 7(a), where the peaks increase until reaching the stationary state. These VOC emissions are related to an increase of the IL generated by an increase in the gas velocity and thus a decrease in the EBRT. As for the liquid phase, in Figure 11(b) it is possible to observe the influence of the gas velocity and EBRT on the absorption and desorption processes. In this situation, the increase in the amount of carbon dissolved in the water tank is combined with the desorption processes, producing oscillations as in the case of the outlet concentration.

[Figure 11 about here.]

\section{Conclusions}

Industrial biotrickling filters (BTFs) usually employ alternating spraying and nonspraying periods. A software tool to simulate the behaviour of BTFs under this and other typical conditions found in industrial facilities has been presented. The partial differential equations of the BTF model have been solved numerically using the method of lines. In 
particular, the software also allows simulating the treatment of volatile organic compound (VOC) air emissions under variable inlet concentrations and gas velocities. The model was calibrated and validated by using data from a biotrickling filter treating isopropanol under intermittent conditions of loading and spraying. The capability of the model to reproduce the complex phenomena involved in the dynamic response of the treatment of hydrophilic compounds by biotrickling filters have been proven. Several examples demonstrate that the pattern of the outlet emissions depends on the pattern of the gas velocity and inlet concentration, showing the utility of the tool to assist in the design and operation of BTFs. The software tool presented herein will be a basis for implement new features. For example, it would be interesting to allow multi-component mixtures in order to go deeper into the interaction between pollutants. This and other extensions are left for future research.

\section{Nomenclature}

\section{Acknowledgements}

The research leading to these results has received funding from the People Programme (Marie Curie Actions) of the European Union's Seventh Framework Programme FP7/20072013/ under REA grant agreement number 284949. Financial support from the Ministerio de Economia y Competitividad (Project CTM2010-15031/TECNO) and the General- 
itat Valenciana (PROMETEO/2013/053), Spain, is also acknowledged. Finally, Pau San Valero thanks the Ministerio de Educación, Cultura y Deporte, Spain, for her FPU contract (AP2010-2191).

\section{References}

Deshusses, M. A., Hamer, G., Dunn, I. J., 1995. Behavior of biofilters for waste air biotreatment. 1. dynamic-model development. Envir Sci Tech 29 (4), 1048-1058.

Deshusses, M. A., Shareefdeen, Z., 2005. Modeling of biofilters and biotrickling filters for odor and VOC control applications. In: Shareefdeen, Z., Singh, A. (Eds.), Biotechnology for Odor and Air Pollution Control. Springer Berlin Heidelberg, Germany, pp. 213-231.

Devinny, J. S., Ramesh, J., 2005. A phenomenological review of biofilter models. Chem Eng J 113 (2-3), 187 - 196.

European Commission, 2003. IPPC reference document on best available techniques in common waste water and waste gas treatment/management systems in the chemical sector. Tech. rep., European Commission.

Fan, L.-S., Leyva-Ramos, R., Wisecarver, K. D., Zehner, B. J., 1990. Diffusion of phenol through a biofilm grown on activated carbon particles in a draft-tube three-phase 
fluidized-bed bioreactor. Biotechnol Bioeng 35 (3), 279-286.

URL http://dx.doi.org/10.1002/bit. 260350309

Ikemoto, S., Jennings, A. A., Skubal, K. L., 2006. Modeling hydrophobic voc biofilter treatment in the presence of nutrient stimulation and hydrophilic VOC inhibition. Environ Modell Softw 21 (10), 1387 - 1401.

Kim, S., Deshusses, M. A., 2003. Development and experimental validation of a conceptual model for biotrickling filtration of $H_{2} S$. Environ Prog 22 (2), 119-128. URL http://dx.doi.org/10.1002/ep.670220214

Lee, S.-h., Heber, A. J., 2010. Ethylene removal using biotrickling filters: part ii. parameter estimation and mathematical simulation. Chem Eng J 158 (2), 89 - 99. URL http://www. sciencedirect.com/science/article/pii/S1385894709008900

Lu, C., Chang, K., Hsu, S., 2004. A model for treating isopropyl alcohol and acetone mixtures in a trickle-bed air biofilter. Process Biochem 39 (12), 1849 - 1858. URL http://www. sciencedirect.com/science/article/pii/S0032959203003650

Álvarez Hornos, F. J., Gabaldón, C., Martínez-Soria, V., Marzal, P., Penya-roja, J.-M., 2009. Mathematical modeling of the biofiltration of ethyl acetate and toluene and their mixture. Biochem Eng J 43 (2), 169 - 177. 
Mannucci, A., Munz, G., Mori, G., Lubello, C., 2012. Biomass accumulation modelling in a highly loaded biotrickling filter for hydrogen sulphide removal. Chemosphere $88(6), 712-717$.

URL http://www.sciencedirect.com/science/article/pii/S004565351200536X

Mpanias, C. J., Baltzis, B. C., 1998. An experimental and modeling study on the removal of mono-chlorobenzene vapor in biotrickling filters. Biotechnol Bioeng 59 (3), 328343.

Métris, A., Gerrard, A. M., Cumming, R. H., Weigner, P., Paca, J., 2001. Modelling shock loadings and starvation in the biofiltration of toluene and xylene. J Chem Technol Biot $76(6), 565-572$.

URL http://dx.doi.org/10.1002/jctb. 422

Okkerse, W. J. H., Ottengraf, S. P. P., Osinga-Kuipers, B., Okkerse, M., 1999. Biomass accumulation and clogging in biotrickling filters for waste gas treatment. evaluation of a dynamic model using dichloromethane as a model pollutant. Biotechnol Bioeng $63(4), 418-430$.

Ottengraf, S. P. P., Van Den Oever, A. H. C., 1983. Kinetics of organic compound removal from waste gases with a biological filter. Biotechnol Bioeng 25 (12), 3089-3102. 
Popat, S. C., Deshusses, M. A., 2010. Analysis of the rate-limiting step of an anaerobic biotrickling filter removing TCE vapors. Process Biochem 45 (4), 549-555.

Reid, R. C., Prausnitz, J. M., Polling, B., 1987. New York, EEUU.

Rene, E. R., Veiga, M. C., Kennes, C., 2013. Biofilters. In: Veiga, M. C., Kennes, C. (Eds.), Air Pollution Prevention and Control: bioreactors and bioenergy. John Wiley \& Sons, Ltd., United Kingdom, pp. 59-119.

San-Valero, P., Penya-Roja, J., Sempere, F., Gabaldón, C., 2013. Biotrickling filtration of isopropanol under intermittent loading conditions. Bioproc Biosyst Eng 36 (7), 975984.

URL http://dx.doi.org/10.1007/s00449-012-0833-y

San-Valero, P., Penya-Roja, J. M., Álvarez Hornos, F. J., Gabaldón, C., 2014. Modelling mass transfer properties in a biotrickling filter for the removal of isopropanol. Chem Eng Sci 108 (0), 47 - 56.

URL http://www. sciencedirect.com/science/article/pii/S0009250913008282

Sander, R., 2005. Henry's law constants in NIST Chemistry WebBook. In: Linstrom, P., Mallard, W. (Eds.), NIST standard reference database number 69. National Institute of Standards and Technology, Gaithersburg MD, 20899.

URL http://webbook.nist.gov 
Schiesser, W. E., 1991. The Numerical Method of Lines. Academic Press.

Schiesser, W. E., 1994. Computational mathematics in Engineering and Applied Science: ODEs, DAEs and PDEs. CRC Press.

Schiesser, W. E., Griffiths, G. W., 2009. A Compendium of Partial Differential Equation Models: Method of Lines Analysis with Matlab. Cambridge University Press.

Sempere, F., Gabaldón, C., Martínez-Soria, V., Marzal, P., Penya-roja, J. M., Álvarez Hornos, F. J., 2008. Performance evaluation of a biotrickling filter treating a mixture of oxygenated VOCs during intermittent loading. Chemosphere 73 (9), 1533-1539.

Sempere, F., Martínez-Soria, V., Penya-roja, J.-M., Izquierdo, M., Palau, J., Gabaldón, C., 2010. Comparison between laboratory and pilot biotrickling filtration of air emissions from painting and wood finishing. J Chem Technol Biot 85 (3), 364-370.

Shareefdeen, Z., Baltzis, B. C., 1994. Biofiltration of toluene vapor under steady-state and transient conditions - theory and experimental results. Chem Eng Sci 49 (24A), 43474360.

Tucker, W. A., Nelken, L. H., 1982. Diffusion coefficients in air and water. In: Lyman, W. J., Reehl, W. F., Rosenblatt, D. H. (Eds.), Handbook of Chemical Property Estimation Methods. American Chemical Society, Ch. 17. 
507

Webster, T. S., Cox, H. H. J., Deshusses, M. A., 1999. Resolving operational and performance problems encountered in the use of a pilot/full-scale biotrickling fiber reactor. Environ Prog 18 (3), 162-172.

Zarook, S. M., Shaikh, A. A., Ansar, Z., 1997. Development, experimental validation and dynamic analysis of a general transient biofilter model. Chem Eng Sci 52 (5), 759-773.

Zhu, X. Q., Alonso, C., Suidan, M. T., Cao, H. W., Kim, B. J., Kim, B. R., 1998. The effect of liquid phase on VOC removal in trickle-bed biofilters. Water Sci Technol 38 (3), 315322. 


\section{List of Figures}

1 Diagram of a BTF. Liquid recirculation only happens during spraying periods. ............................ 34

2 Mechanisms involved in the process of BTF . . . . . . . . . . . 35

3 Main window of the GUI: Two emission patterns (per day) . . . . . . . . 36

4 GUI of the MATLAB ${ }^{\circledR}$ tool. Dialog for the Ramp+Constant inlet VOC concentration profile. . . . . . . . . . . . . . . 37

5 Spray cycle patterns for one day. Emission pattern 1 has three cycles $\left(n_{1}=3\right)$, and emission pattern 2 has two $\left(n_{2}=2\right)$ spray cycles. The user specifies $T_{s_{1}}, n_{1}, T_{1}, T_{s_{2}}$, and $n_{2}$. Non-spray times are given by $T_{n s_{1}}=\left(T_{1}-\right.$ $\left.\left.n_{1} T_{s_{1}}\right) / n_{1}\right)$ and $T_{n s_{2}}=\left(T_{2}-n_{2} T_{S_{2}}\right) / n_{2}$ for emission pattern 1 and emission pattern 2, respectively. . . . . . . . . . . . . . . 38

6 GUI of the MATLAB ${ }^{\circledR}$ tool (results window). . . . . . . . . . . . . . . 39

$7 \quad$ Model Calibration with experimental data from San-Valero et al. (2013) . 40

$8 \quad$ Model Validation with experimental data from San-Valero et al. (2013) . . 41

9 Effect in the dynamic response of the BTF to oscillating inlet concentration 42

10 Effect in the dynamic response of the BTF to oscillating inlet concentration combined with spraying times during non-VOC feeding periods . . . 43

11 Effect in the dynamic response of the BTF to oscillating gas flow rates . . 44 


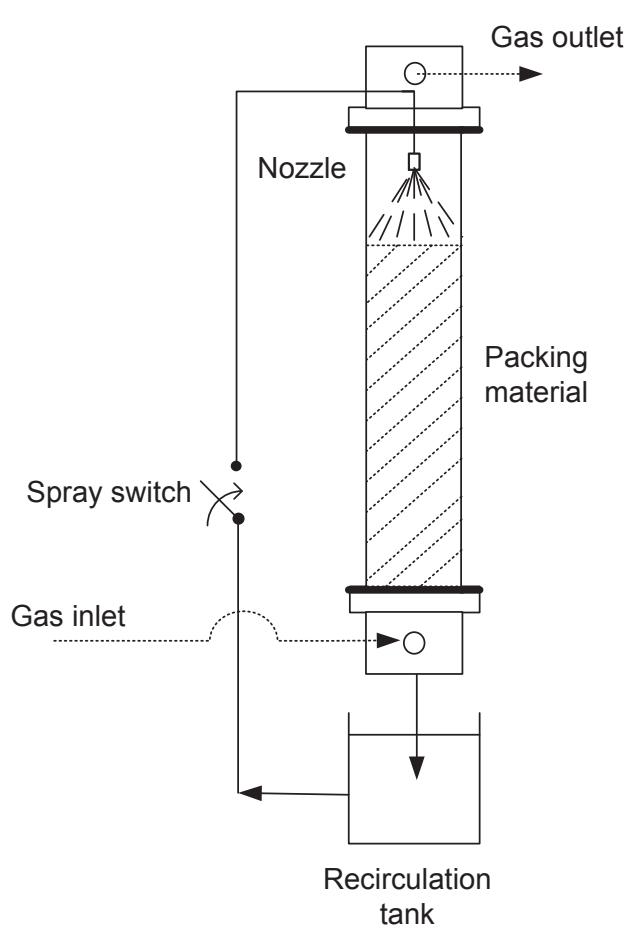

Figure 1: Diagram of a BTF. Liquid recirculation only happens during spraying periods. 


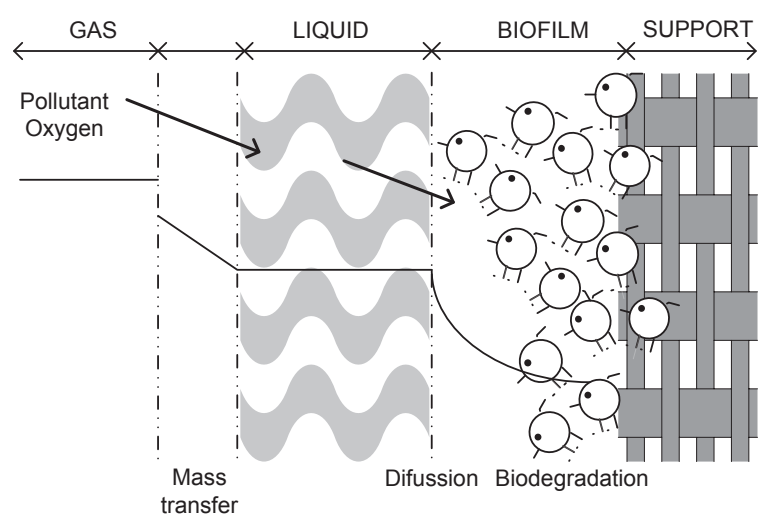

Figure 2: Mechanisms involved in the process of BTF 


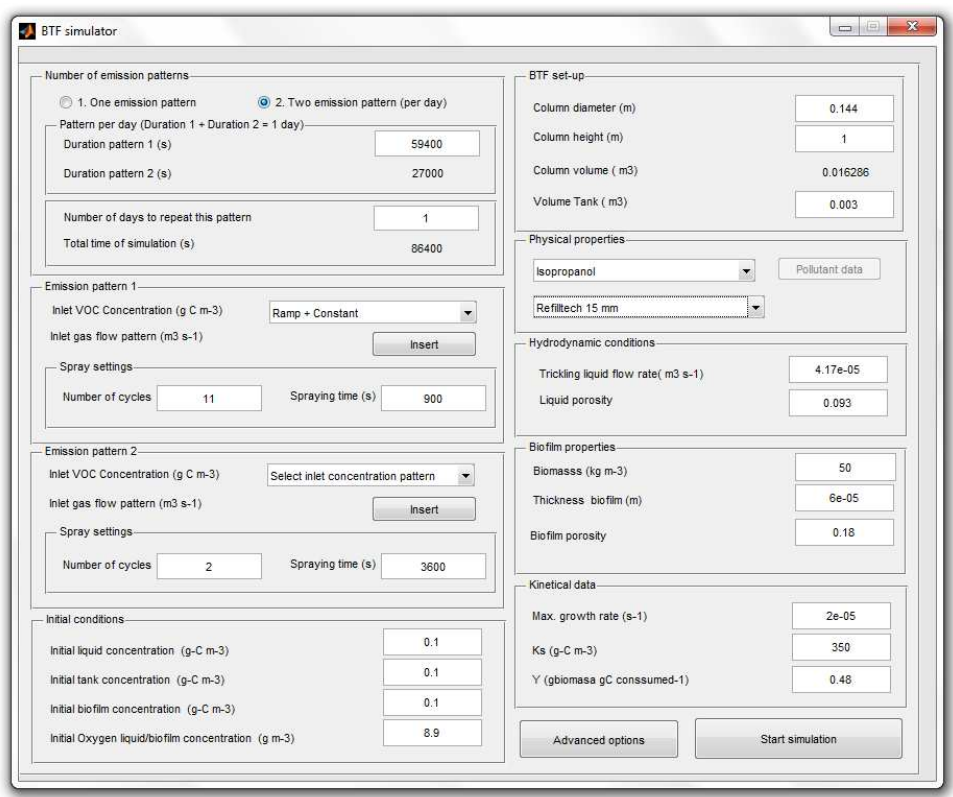

Figure 3: Main window of the GUI: Two emission patterns (per day) 


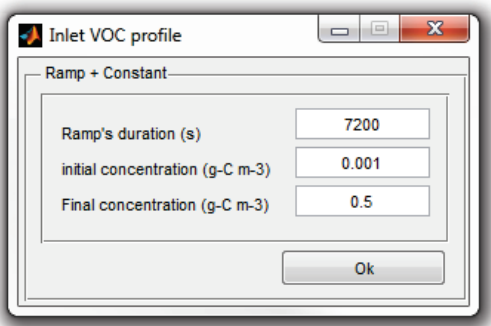

Figure 4: GUI of the MATLAB ${ }^{\circledR}$ tool. Dialog for the Ramp+Constant inlet VOC concentration profile. 


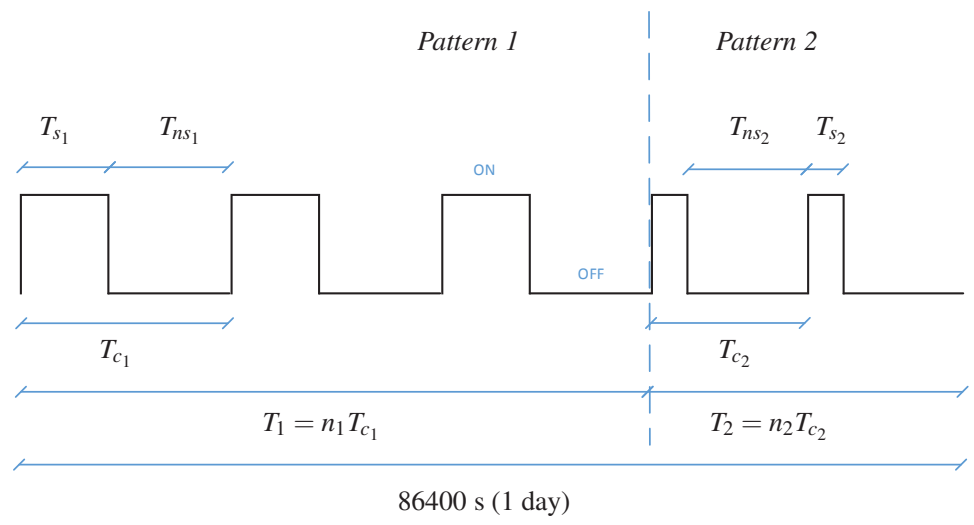

Figure 5: Spray cycle patterns for one day. Emission pattern 1 has three cycles $\left(n_{1}=3\right)$, and emission pattern 2 has two $\left(n_{2}=2\right)$ spray cycles. The user specifies $T_{s_{1}}, n_{1}, T_{1}, T_{s_{2}}$, and $n_{2}$. Non-spray times are given by $T_{n s_{1}}=$ $\left.\left(T_{1}-n_{1} T_{S_{1}}\right) / n_{1}\right)$ and $T_{n s_{2}}=\left(T_{2}-n_{2} T_{S_{2}}\right) / n_{2}$ for emission pattern 1 and emission pattern 2 , respectively. 


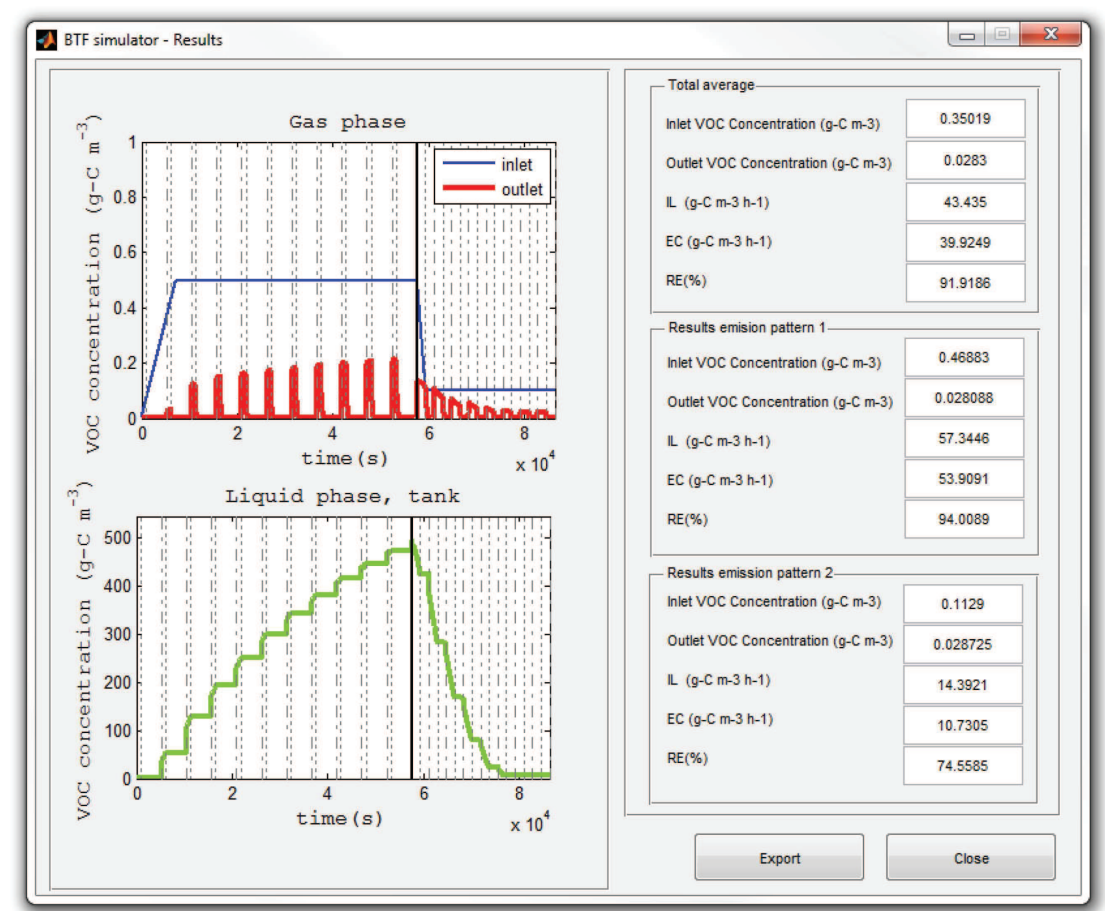

Figure 6: GUI of the MATLAB ${ }^{\circledR}$ tool (results window). 


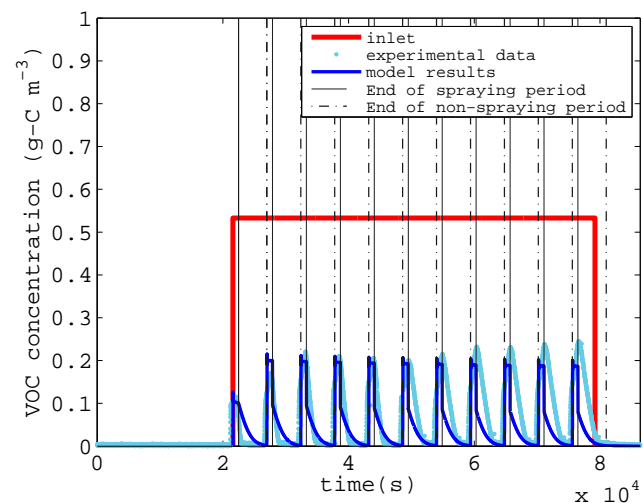

(a) Evolution of the concentration in the gas phase

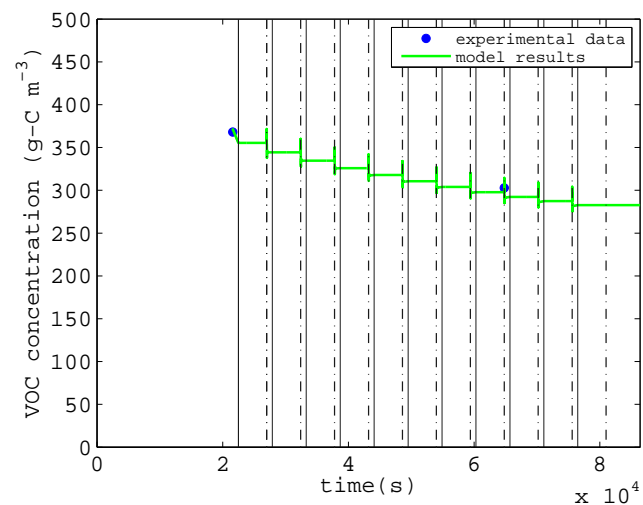

(b) Evolution of the dissolved organic carbon in the recirculation tank

Figure 7: Model Calibration with experimental data from San-Valero et al. (2013) 

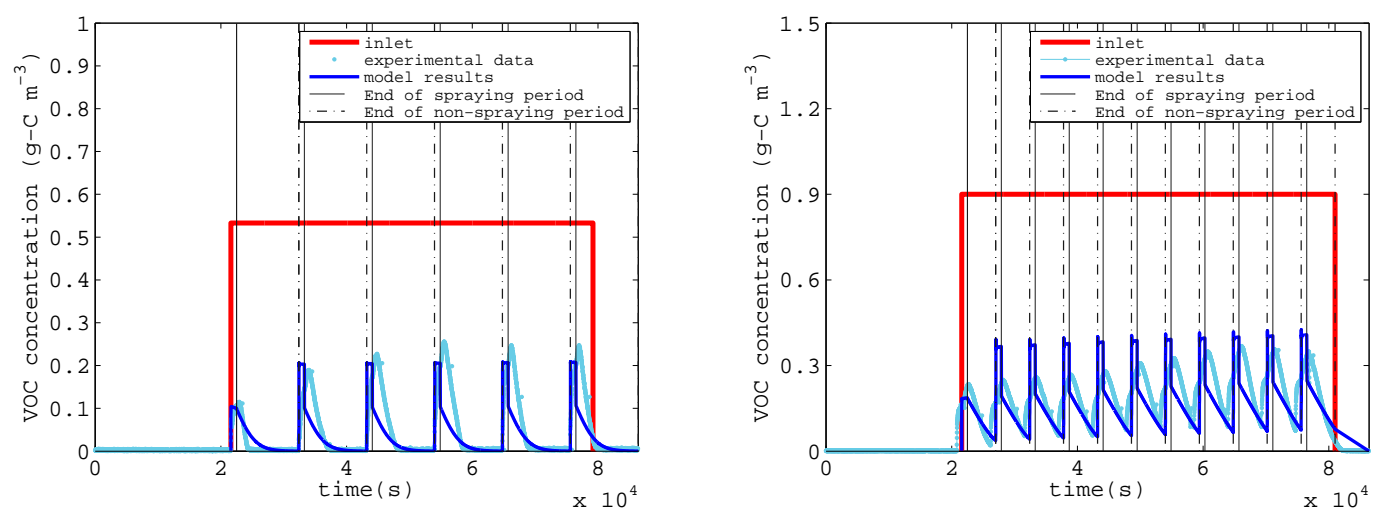

(a) Spraying regime 15 min every $3 \mathrm{~h}$ and IL $32 \mathrm{~g}-\mathrm{C}$ (b) Spraying regime 15 min every $1.5 \mathrm{~h}$ and IL $65 \mathrm{~g}$ $\mathrm{m}^{-3} \mathrm{~h}^{-1}$ $-\mathrm{C} \mathrm{m} \mathrm{m}^{-3} \mathrm{~h}^{-1}$

Figure 8: Model Validation with experimental data from San-Valero et al. (2013) 


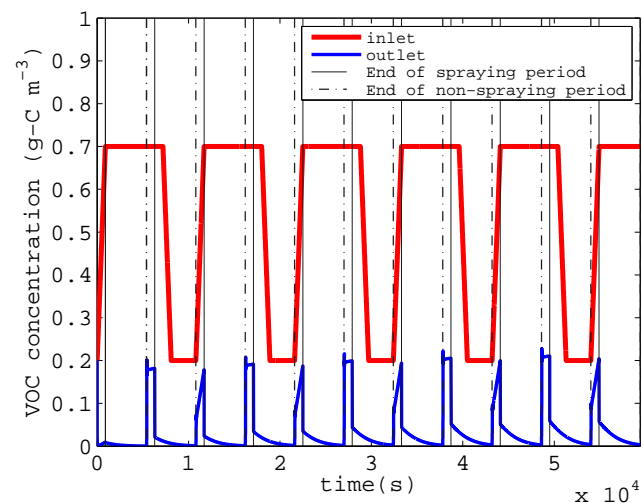

(a) Evolution of the concentration in the gas phase

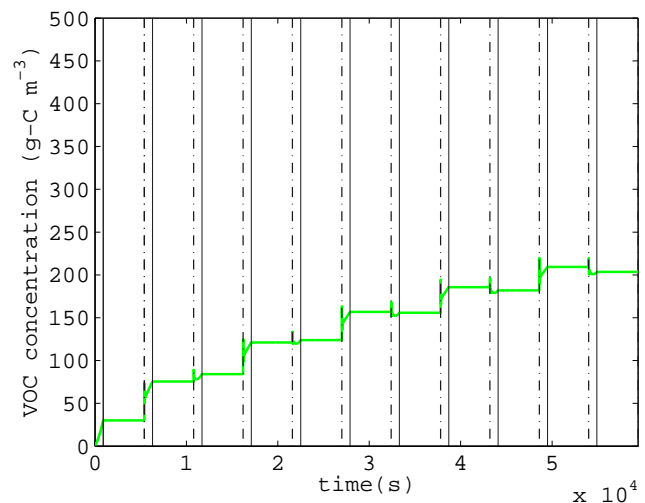

(b) Evolution of the dissolved organic carbon in the recirculation tank

Figure 9: Effect in the dynamic response of the BTF to oscillating inlet concentration 


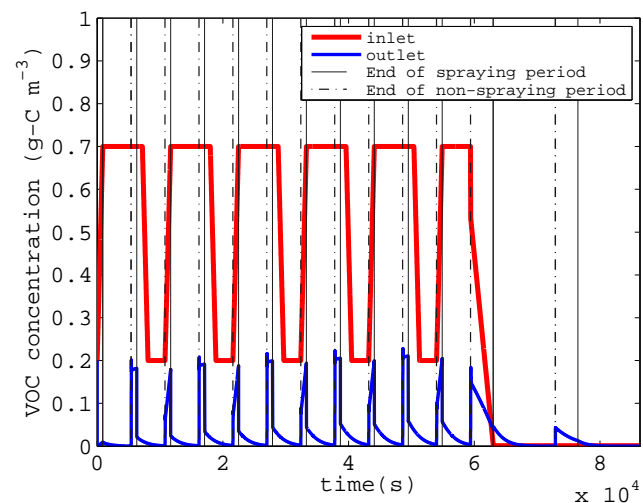

(a) Evolution of the concentration in the gas phase

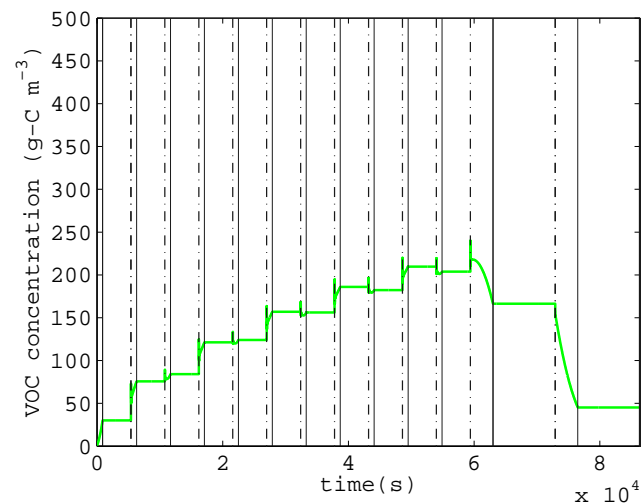

(b) Evolution of the dissolved organic carbon in the recirculation tank

Figure 10: Effect in the dynamic response of the BTF to oscillating inlet concentration combined with spraying times during non-VOC feeding periods 

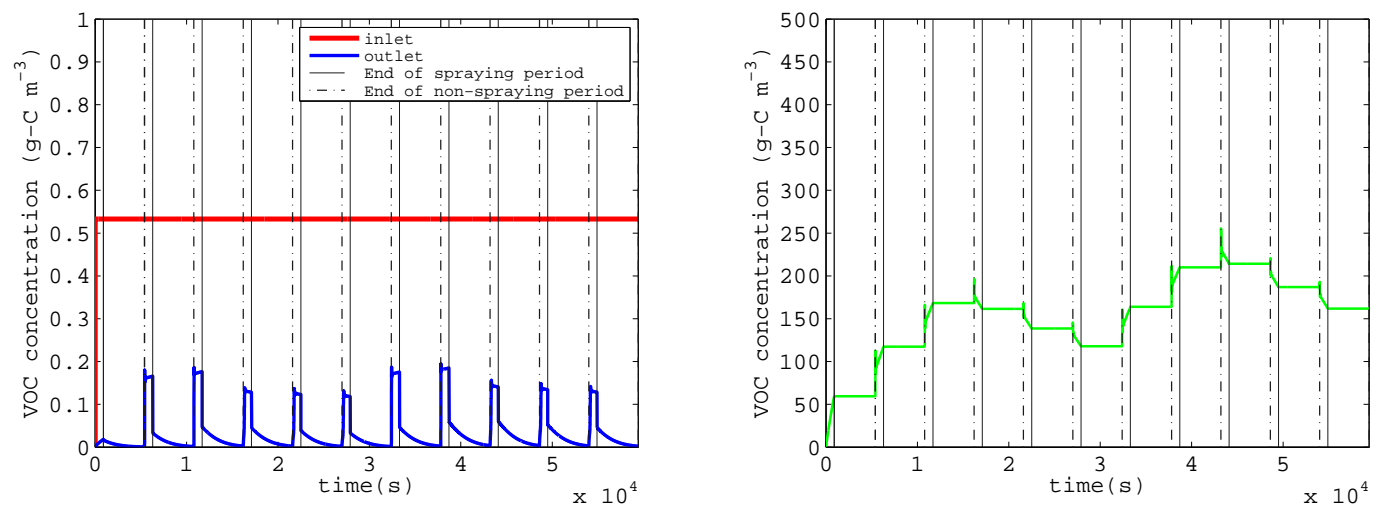

(a) Evolution of the concentration in the gas phase

(b) Evolution of the dissolved organic carbon in the recirculation tank

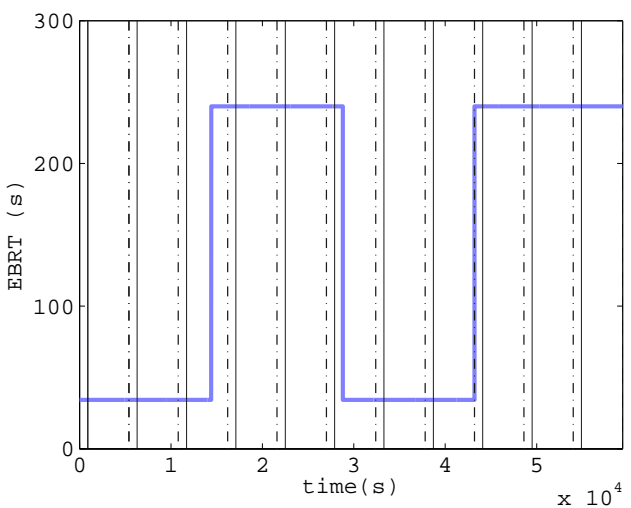

(c) Evolution of the EBRT

Figure 11: Effect in the dynamic response of the BTF to oscillating gas flow rates 
${ }_{534} \quad$ List of Tables

$535 \quad 1$ Model parameters used in the mathematical model . . . . . . . . . 46 


\begin{tabular}{|c|c|c|c|}
\hline Variable & Specific Value & Units & Reference \\
\hline \multicolumn{4}{|c|}{ Experimental parameters } \\
\hline$A_{v}$ & 348 & $m^{-1}$ & San-Valero et al. (2013) \\
\hline$D$ & 0.144 & $\mathrm{~m}$ & San-Valero et al. (2013) \\
\hline$D_{P_{w}}$ & $1.13 \times 10^{-9}$ & $\mathrm{~m}^{2} \mathrm{~s}^{-1}$ & Tucker and Nelken (1982) \\
\hline$D_{O_{w}}$ & $2 \times 10^{-9}$ & $\mathrm{~m}^{2} \mathrm{~s}^{-1}$ & Reid et al. (1987) \\
\hline$H_{P}$ & $2.8 \times 10^{-4}$ & & San-Valero et al. (2014) \\
\hline$H_{O}$ & 31.4 & & Sander (2005) \\
\hline$K_{L} a_{P}$ & $\frac{H_{P}}{3600}\left(11.59\left(v_{G} 3600\right)^{0.85}\right)$ & $\mathrm{s}^{-1}$ & San-Valero et al. (2014) \\
\hline$K_{L} a_{0}$ & $1.15 \times 10^{-2}$ & $\mathrm{~s}^{-1}$ & San-Valero et al. (2014) \\
\hline$Q_{L}$ & $41.7 \times 10^{-6}$ & $\mathrm{~m}^{3} \mathrm{~s}^{-1}$ & San-Valero et al. (2013) \\
\hline$V_{R}$ & 0.0163 & $\mathrm{~m}^{3}$ & San-Valero et al. (2013) \\
\hline$V_{T}$ & 0.003 & $\mathrm{~m}^{3}$ & San-Valero et al. (2013) \\
\hline$Y_{P}$ & 0.48 & $\frac{\mathrm{g} \text { biomass }}{\text { g consumed }}$ & Lu et al. (2004) \\
\hline$Y_{O}$ & 0.14 & $\frac{\mathrm{g} \text { biomass }}{\mathrm{g} \text { consumed }}$ & Stoichiometric balance \\
\hline$Z$ & 1 & $\mathrm{~m}$ & San-Valero et al. (2013) \\
\hline$\theta_{B}$ & 0.18 & & This work \\
\hline$\theta_{L}$ & 0.093 & & This work \\
\hline \multicolumn{4}{|c|}{ Calibration parameters } \\
\hline$K_{S_{P}}$ & 350 & \multicolumn{2}{|l|}{$\mathrm{g}-\mathrm{C} \mathrm{m}^{-3}$} \\
\hline$X_{v}$ & $50 \times 10^{3}$ & \multicolumn{2}{|l|}{$\mathrm{g} \mathrm{m}^{-3}$} \\
\hline$\alpha_{1}$ & \multicolumn{3}{|c|}{0.23 (except for cycle 1 that takes $\left.\alpha_{1}=1\right)$} \\
\hline$\beta$ & $6.4 \times 10^{-6}$ & \multicolumn{2}{|l|}{$\mathrm{m}$} \\
\hline$\delta$ & $60 \times 10^{-6}$ & \multicolumn{2}{|l|}{$\mathrm{m}$} \\
\hline$\mu_{\max }$ & $2 \times 10^{-5}$ & \multicolumn{2}{|l|}{$\mathrm{s}^{-1}$} \\
\hline
\end{tabular}

Table 1: Model parameters used in the mathematical model 


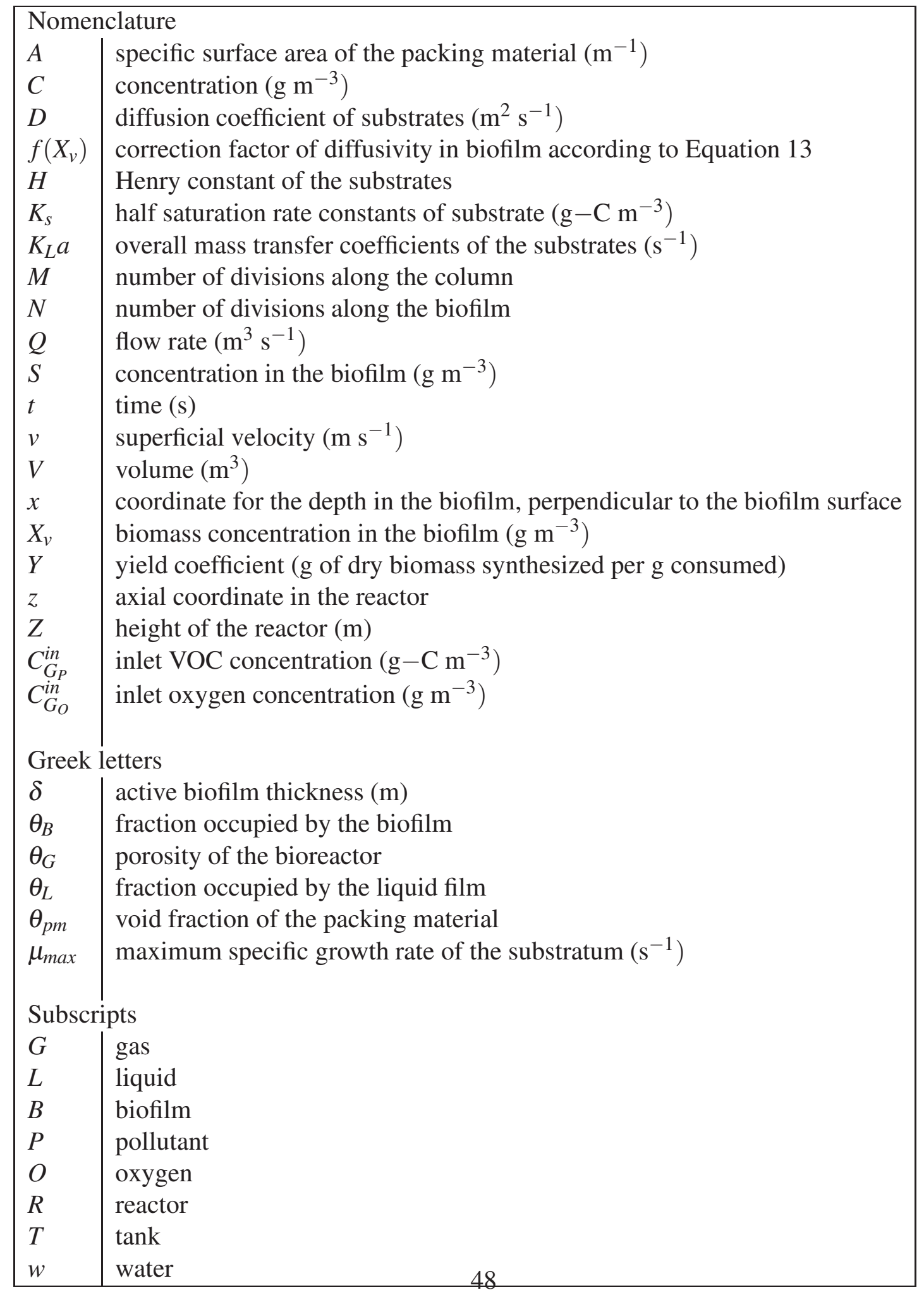

